\title{
吉林陨石样品的冲击加载实验研究*
}

\author{
戴诚达王道德 \\ 金 孝 刚 \\ (中国科学院地球化学研究所, 贵阳 550002) (西南流体物理䂺究所, 绵阳 610003)
}

关钺词吉林陨石、冲击变质、冲击相

陨石中残留的各种冲击效应是其母体间高速碰撞碎裂时产生的. 利用动高压装置对陨石 样品进行冲击加载, 对回收样品的冲击效应加以系统

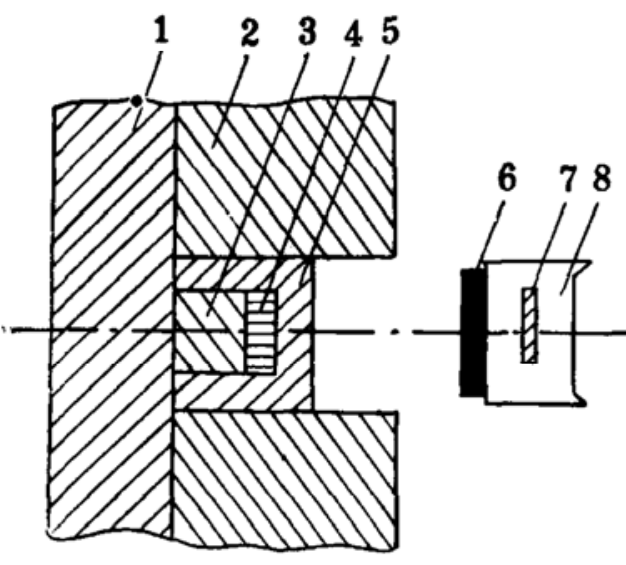

图 1 样品安装和冲击回收装置示意图

1.底板；2.保护环；3.塞子；4.样品；

5.样品容器；6.飞片；7.小磁铁；8.弹托 研究, 可以获得陨石中各种主要冲击特征形成的压力 和温度范围, 推测陨石母体间碰撞的动力学条件和空 间环境.Sears 等 ${ }^{[1]}$ 曾对陨石样品 (Kernouve 球粒隄 石, $\mathrm{H}_{6}$ ) 进行过冲击加载实 验研究, 获得了 7.0一 $39.0 \mathrm{GPa}$ 压力范围内的 4 个冲击样品. 由于受回收样 品量的限制,未能对冲击样品进行系统的矿物学、岩石 学和地球化学研究,对各种显微冲击特征的压标、冲击 相压力范围等重要问题未作进一步的探 讨. 除 此之 外, 未见其它类似的报道.

本文报道了以吉林陨石 $\left(\mathrm{H}_{5}\right)$ 为初始物质在动高 压装置上进行冲击加载实验, 成功地回收到了 12.4$132.5 \mathrm{GPa}$ 冲压范围内的 8 个冲击样品, 并对这些样 品进行了矿相学和岩石学研究, 建立了陨石冲击变质 程度的判别标准.

\section{一、实 验方法}

冲击加载实验是在成都科技大学 $\varnothing 23 \mathrm{~mm}$ 内口径的二级轻气炮动高压装置上进行的. 实验样品制成 $\varnothing 10 \mathrm{~mm} \times 2 \mathrm{~mm}$ 的小圆片. 样品预先装入回收容器内, 然后用高速弹丸撞击 样品容器, 产生平面冲击波, 使样品受到冲击加载. 图 1 是样品安装和冲击回收装置的示意 图. 实验中由于高速碰撞的成坑效应会导致冲击样品的丢失, 故适当控制了弹丸击靶速度 $(<4 \mathrm{~km} / \mathrm{s})$, 冲击加载压力的提高主要用改变飞片材料和采用二次冲击增压技术 ${ }^{[2]}$ 的方法 来 实现. 飞片采用聚碳酸脂、 $\mathrm{Ly}-12 \mathrm{Al}$ 和铜. 用铜或铇片作冲击波反射材料. 弹丸击靶速度用 磁飞行体法 ${ }^{[3]}$ 测量. 冲击压力用阻抗匹配法 ${ }^{[4]}$ 求出. 冲击温度和残余温度用数值计算法 ${ }^{[5}$ 求 得. 吉林陨石样品的冲击加载条件列于表 1 .

本文 1990 年11月19日收到.

- 国家自然科学基金资助项目. 
表 1 吉林陨石样品的冲击加载条件

\begin{tabular}{|c|c|c|c|c|c|c|c|c|}
\hline \multirow{2}{*}{ 哅 } & \multirow{2}{*}{ 号 } & \multirow{2}{*}{ 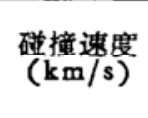 } & \multicolumn{2}{|c|}{ 冲区 $(\mathrm{GPa})$} & \multirow{2}{*}{ 冲击温) } & \multirow{2}{*}{ 残余温度 } & \multirow{2}{*}{ 㸝材料 } & \multirow{2}{*}{$\begin{array}{c}\text { 高阻抗 } \\
\text { 增压材料 }\end{array}$} \\
\hline & & & 初始压力 & 帮值压力 & & & & \\
\hline & & 2.508 & 8.0 & 12.4 & 336 & 297 & Lexan & $\mathrm{Cu}_{\mathrm{u}}$ \\
\hline & & 2.258 & 18.2 & 27.3 & 472 & 386 & $\mathrm{Ly}-12 \mathrm{Al}$ & $\mathrm{Cu}$ \\
\hline & & 2.621 & 39.0 & 39.0 & 624 & 502 & $\mathrm{Cu}$ & 1 \\
\hline & & 2.388 & 35.0 & 53.0 & 720 & 550 & $\mathrm{Cu}$ & $\mathrm{Cu}$ \\
\hline & & 2.691 & 40.5 & 77.5 & 1120 & 832 & $\mathrm{Cu}$ & $w$ \\
\hline & & 2.826 & 43.4 & 82.8 & 1249 & 925 & $\mathrm{Cu}$ & w \\
\hline & & 3.066 & 48.2 & 92.6 & 1460 & 1064 & $\mathrm{Cu}_{\mathrm{u}}$ & $\mathbf{w}$ \\
\hline & & 3.927 & 68.5 & 132.5 & 2426 & 1725 & $\mathrm{Cu}$ & $\mathbf{w}$ \\
\hline
\end{tabular}

\section{二、结果与讨论}

1. 显微冲击特征把上述 8 个冲击样品分别制成光片和薄片, 在反光和偏光显微镜下 观察,其显微冲击特征列于表 2 .

表 2 吉林陨石冲击加载样品的显微冲击特征

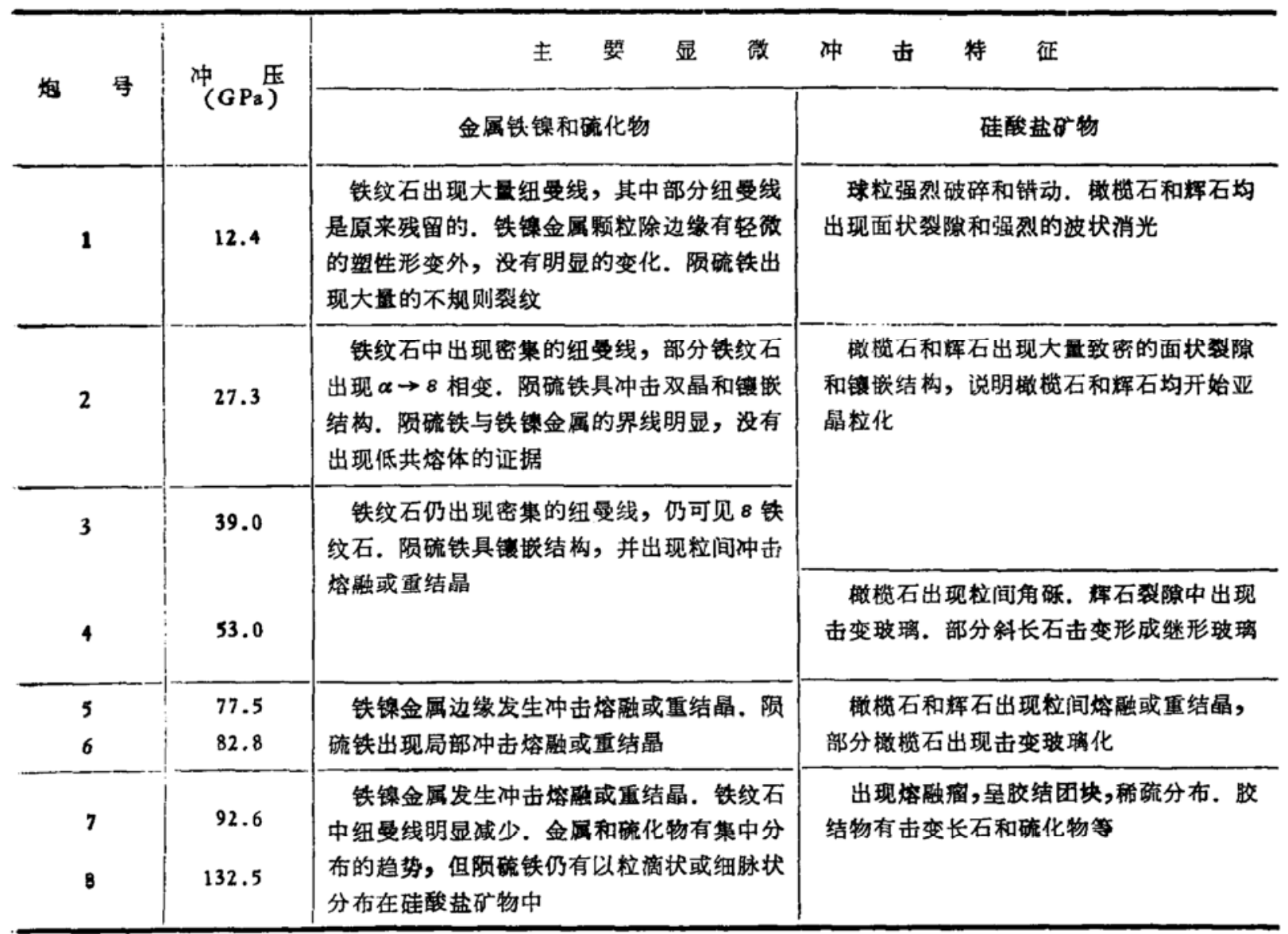

我们根据已知冲压的冲击样品特征结构, 对 Dodd 和 Jarosewich ${ }^{[6]}$ 的冲击相压力范围以 进行了重新标定 (表 3), 并补充和完善了普通球粒陨石冲击变质强度的划分标准. 根据吉林 陨石天然样品的冲击特征 ${ }^{[8]}$, 确定吉林陨石冲击变质形成的冲压大约为 $15-20 \mathrm{GPa}$, 冲击变质 
表 3 普通球粒陨石冲击变质强度的分级

\begin{tabular}{|c|c|c|c|c|}
\hline \multirow{2}{*}{ 冲击强度 } & \multirow{2}{*}{$\begin{array}{c}\text { 冲击相 } \\
\text { (Dodd 等, } \\
\text { 1979) }\end{array}$} & \multicolumn{2}{|c|}{ 冲屯压力 $(\mathrm{GPa})$} & \multirow{2}{*}{ 主要冲击特征 } \\
\hline & & $\begin{array}{l}\text { Stöffler } \\
\text { (1988) }\end{array}$ & 本 文 & \\
\hline 0 & $\mathbf{a}$ & $0-5$ & $0-5$ & 铁纹石出现纽曼线; 硅酸蓝矿物不规则破裂 \\
\hline I & $b+c$ & $5-20$ & $5-20$ & 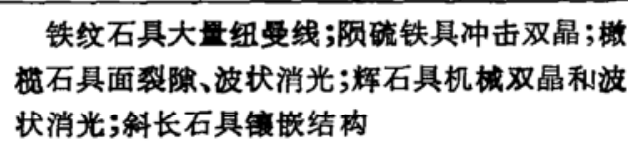 \\
\hline II & d & $20-30$ & $20-40$ & 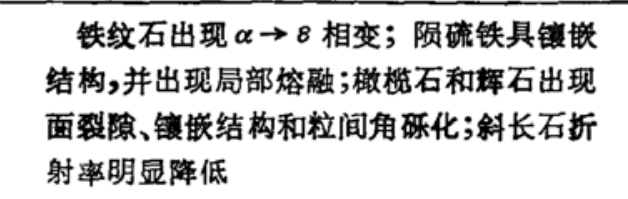 \\
\hline III & e & $30-45$ & $40-70$ & 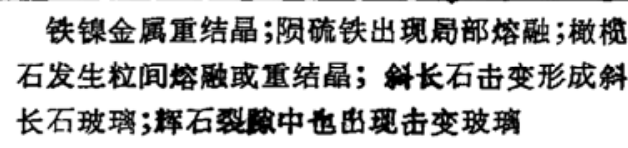 \\
\hline IV & $\mathbf{f}$ & $45-80$ & $70-100$ & 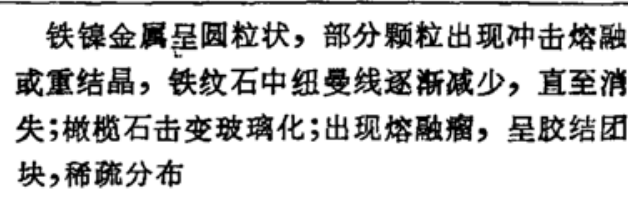 \\
\hline $\mathbf{v}$ & g & $>80$ & $>100$ & 熔融瘤、玻琌脉和全岩嫆蜸(？） \\
\hline
\end{tabular}

强度为 I 级, 属 $\mathrm{b}+\mathrm{c}$ 冲击相.

2. 䃌化学组成的变化特征为了考察冲击加载对矿物化学组成的影响, 对 $12.4,53.0$ 和 $82.8 \mathrm{GPa} 3$ 个冲击样品中的铁纹石、镍纹石、陨硫铁、橄榄石和斜方辉石作了电子探针分析, 其结果列于表 4 和表 5 中.

表 43 个冲击样品中铁镍金属和硫化物的化学组成 (wt\%)

\begin{tabular}{|c|c|c|c|c|c|c|c|c|c|c|c|}
\hline $\begin{array}{c}\text { 冲压 } \\
(\mathrm{GPa})\end{array}$ & 矿 物 & 颗粒数 & $\mathrm{Fe}$ & $\mathrm{Ni}$ & Co & $\mathrm{Cr}_{\mathrm{r}}$ & $\mathrm{s}$ & 总䡒 & $\sigma \mathrm{Fe}^{*}$ & $\sigma \mathrm{Ni}$ & $\sigma \mathrm{S}$ \\
\hline \multirow{3}{*}{12.4} & 纹石 & 8 & 92.05 & 6.63 & 0.63 & 0.11 & 0.03 & 99.45 & 1.10 & 1.05 & \multirow[b]{3}{*}{2.62} \\
\hline & 嵲纹石 & 13 & 58.39 & 40.14 & 0.17 & 0.15 & 0.20 & 99.05 & 8.46 & 8.37 & \\
\hline & 陨硫铁 & 11 & 62.21 & 0.24 & 0.04 & 0.02 & 36.22 & 98.73 & 2.25 & & \\
\hline \multirow{3}{*}{53.0} & 铁纹石 & 9 & 92.62 & 5.65 & 0.59 & 0.12 & 0.04 & 99.02 & 0.66 & 0.34 & \multirow[b]{3}{*}{2.01} \\
\hline & 镍坟石 & 9 & 66.05 & 32.46 & 0.13 & 0.13 & - & 98.77 & 1.68 & 1.53 & \\
\hline & 陨硫铁 & 12 & 62.63 & 0.16 & 0.05 & 0.03 & 35.90 & 98.77 & 1.63 & & \\
\hline \multirow{3}{*}{82.8} & 铁纹石 & 12 & 92.28 & 6.16 & 0.57 & 0.09 & 0.04 & 99.14 & 0.32 & 0.33 & \multirow[b]{3}{*}{1.16} \\
\hline & 锈纹石 & 5 & 51.57 & 46.77 & 0.14 & 0.13 & - & 98.61 & 0.58 & 0.96 & \\
\hline & 闾磷失 & 8 & 62.81 & 0.06 & 0.04 & - & 36.10 & 99.01 & 0.98 & & \\
\hline
\end{tabular}

* $\sigma$ : 标准偏差. 一：含賹 $<0.01 \%$. 
表 53 个冲击样品中㯙榄石和科方辉石的化学组成 (wt\%)

\begin{tabular}{|c|c|c|c|c|c|c|c|c|c|c|c|c|c|c|c|}
\hline $\begin{array}{c}\text { 冲医 } \\
(\mathrm{GPa})\end{array}$ & 矿物 & 颗粒数 & $\mathrm{SiO}_{2}$ & $\mathrm{TiO}_{2}$ & $\mathrm{Al}_{2} \mathrm{O}_{3}$ & $\mathrm{Cr}_{2} \mathrm{O}_{3}$ & $\mathrm{FeO}$ & $\mathrm{MnO}$ & $\mathrm{MgO}$ & $\mathrm{C}_{2} \mathrm{O}$ & $\mathrm{K}_{2} \mathrm{O}$ & $\mathrm{Na}_{2} \mathrm{O}$ & 总量 & $\overline{\mathrm{F}}_{\mathrm{a}}\left(\overline{\mathrm{F}}_{\mathrm{s}}\right)^{*}$ & $\sigma * *$ \\
\hline \multirow{2}{*}{12.4} & 做枚石 & 10 & 38.81 & 0.04 & 0.01 & 0.03 & 17.73 & 0.48 & 42.86 & 0.04 & 0.01 & 0.01 & $100 \cdot 02$ & 18.2 & 0.51 \\
\hline & 斜方辉石 & 10 & 56.55 & 0.09 & 0.11 & 0.11 & 11.15 & 0.48 & 31.34 & 0.52 & 0.01 & 0.03 & 100.39 & 16.5 & 0.43 \\
\hline \multirow{2}{*}{53.0} & 倣㭠石 & 10 & 38.87 & 0.06 & 0.03 & 0.06 & 17.65 & 0.47 & 42.20 & 0.05 & 0.01 & 0.02 & 99.42 & 19.0 & 0.47 \\
\hline & 斜方晖石 & 7 & 55.57 & 0.28 & 0.22 & 0.12 & 11.14 & 0.57 & 30.73 & 0.54 & 0.04 & 0.10 & 99.31 & 16.8 & 0.39 \\
\hline \multirow{2}{*}{82.8} & 橵榄不 & 8 & 38.38 & 0.03 & 0.01 & 0.04 & 17.70 & 0.55 & 42.65 & 0.11 & 0.03 & 0.02 & 99.52 & 18.9 & 0.14 \\
\hline & 斜方辉石 & 8 & 55.14 & 0.09 & 0.16 & 0.10 & 11.35 & 0.53 & 31.22 & 0.48 & 0.05 & 0.03 & 99.15 & 16.9 & 0.31 \\
\hline
\end{tabular}

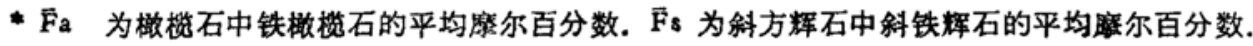

** $\sigma$ 表示 $\mathrm{Fa}_{\mathrm{a}}$ 或 $\mathrm{F}_{8}$ 的标准偏差.

表 4 和 5 中的数据清楚地表明,随着冲击加载压力的提高, 铁纹石、镍纹石、陨硫铁、橄䈭 石和斜方辉石的化学组成都具均一化趋势. 而檦榄石中的铁橄榄石 ( $\mathrm{Fa}$ ) 和斜方辉石中的斜 铁辉石 (Fs) 的摩尔百分含量基本保持稳定. 因此, 冲击加载并不改变球粒陨石的原始化 学一一岩石类型.

\section{参考文献}

[1] Sears, D. W. et al., Geochim. Cosmochim. Acto, 48 (1984), 343-360.

[2] 经福谦等著, 实验物态方程导引, 科学出版社, 北京, 1986, 172-173.

[3] Kondo, K. 1. et al., Rev. Sci. Instru., 43 (1977), 1581.

[4] 林文祝, 空间科学学报, 4(1984), 338-345.

[5] 经楆谦等著,实验物态方程导引,科学出版社, 北京, 1986, 320-323.

[6] Dodd, R. T. and Jarosewich, E., Earth Plonet. Sci. Lett., 44 (1979), 335-340.

[7] Stöffler, D. et al., Shock effects in meteorites, in Meteorites and the Early Solar System (Eds. Kerridge, J. F. and Matthews, M. S.), Univ. of Arizora Press, Tucson, 1988, 177.

[8]王道德、谢先德, 地球化学, 1978, 1: 13-18. 